DEPARTMENT OF THE INTERIOR UNITED STATES GEOLOGICAL SURVEY

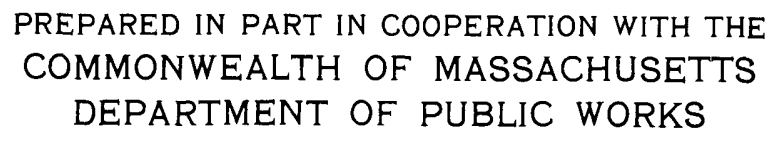

\title{
AEROMAGNETIC MAP OF THE PAWTUCKET QUADRANGLE, PROVIDENCE COUNTY, RHODE ISLAND, AND BRISTOL AND NORFOLK COUNTIES, MASSACHUSETTS
}

GEOPHYSICAL INVESTIGATIONS

MAP GP-780

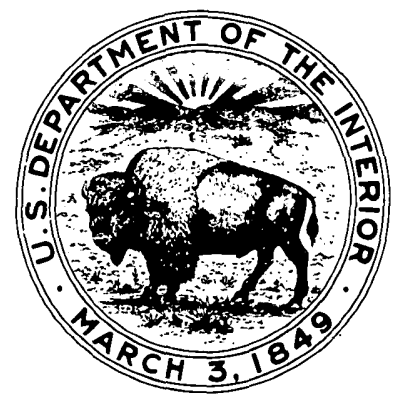

